\title{
A study of students' travellers values and needs in order to establish futures patterns and insights
}

\author{
Elena Cavagnaro and Simona Staffieri
}

\author{
Dr Elena Cavagnaro is UAS \\ Professor of Sustainability in \\ Hospitality and Tourism at the \\ Academy of International \\ Hospitality Research, Stenden \\ Hotel Management School, \\ Stenden University of Applied \\ Sciences, Leeuwarden, \\ The Netherlands. \\ Dr Simona Staffieri is \\ Statisitician at the Italian \\ National Institute of Statistics, \\ Rome, Italy.
}

\footnotetext{
C) Elena Cavagnaro and Simona Staffieri. Published in the Journal of Tourism Futures. This paper is published under the Creative Commons Attribution (CC BY 4.0) licence. Anyone may reproduce, distribute, translate and create derivative works of this paper (for both commercial and non-commercial purposes), subject to full attribution to the original publication and authors.

The full terms of this licence may be seen at: http://creativecommons.org/ licences/by/4.0/legalcode

A draft version of this paper was presented at the CHME conference (University of Derby, Buxton Campus) in May 2014. The authors are grateful for the comments received by the $\mathrm{CHME}$ reviewers: they helped in better focusing the paper and future research.
}

\begin{abstract}
Purpose - If the only viable future for tourism is sustainable tourism then ways should be sought to increase the demand for sustainable offers. The purpose of this paper is to explore whether sustainability values influence the travel needs of students. The aim is to discover cues in the present behaviour of young tourists that can enhance sustainable travel choices and therefore secure the future of the tourism industry. Moreover, the study provides a solid basis for predicting the future travel behaviour of young tourists.

Design/methodology/approach - Data were collected in The Netherlands in 2013 through a survey. A non-probabilistic sample of 365 students (a sub-group of young tourists) was reached. Multivariate analyses were used to test whether position in the social structure and value orientation influence the travel need. The logistic models allowed youth tourism behaviour to be predicted.

Findings - Respondents with a biospheric value orientation associate travel with being in contact with nature and chose rest as a motivation. This is highly interesting from a future perspective because biospheric values are considered the most stable antecedent of sustainable behaviour. Findings also highlight women's role as the sustainable tourists of the future: women harbour strong sustainability values and see travel as a growth opportunity.

Research limitations/implications - This research focuses on travel needs because this is the most future-oriented phase of the tourism experience, and on students because they tend to travel independently. Future research might include travel consumption and evaluation as well as non-students in the sample to give a more balanced view on young tourists. Future research might also include values not related to sustainability to assess their relative strengths in influencing youth tourism.

Practical implications - Both policy makers and industry could capitalise on the sustainability values already present in young people's need for travel to nudge this group - who represents tourism's future - towards a sustainable tourism choice. For example, strengthening sustainability values through marketing and education will increase demand for a sustainable offer.

Originality/value - Values related to sustainability influence general tourism choices by young travellers, and not only choices related to a sustainability offer. This finding suggests a path to address the classic dilemma between individualism and sustainability and assure tourism's future by showing young travellers that they already harbour sustainability values.
\end{abstract}

Keywords Values, Travel motivation, Tourism future, Travel meaning, Youth tourism

Paper type Research paper

\section{Introduction}

Tourism's future greatly depends on its capacity to meet a growing demand without increasing its environmental footprint or its pressure on communities at the destination (United Nations World Tourism Organization (UNWTO), 2013). Simply stated, tourism faces the challenge of becoming sustainable. A major issue experienced by the tourism industry in securing its future is the lack of demand for sustainable offers, both by tourism organisations and individual tourists (Tepelus, 2005). 
Demand for sustainable tourism is usually approached from a marketing perspective (March and Woodside, 2005). This leads to a focus on short-term market choices, and is therefore less appropriate for exploring the effect of future choices on the longer-term perspective required by sustainability. A more suitable approach is offered by sociopsychological theories on the influence of values on sustainable behaviour. Together with the social background of a person, values are considered a stable antecedent of behaviour and might therefore predict not just immediate, but also future choices (Stern et al., 1995; De Groot and Steg, 2008).

Furthermore, most studies on demand for sustainable tourism focus on a particular kind of sustainable offer, such as ecotourism (Perkins and Brown, 2012). They therefore fail to explore whether values linked to sustainable behaviour also exert an influence on other types of offers, including those that are not yet sustainable. As the most effective way to increase future demand for sustainable products and services is to show consumers that they already make sustainable choices in their habitual behaviour (Thøgersen and Ölander, 2003; Steg and Vlek, 2009) there is a need to explore whether motivations linked to sustainability influence travellers' experience in general, i.e. experiences that might and might not include sustainable offers. That is exactly what this study aims to do.

The purchase and consumption of tourist products has three phases: before, during and after the tourism experience. The first phase is usually labelled as "need recognition" and consists of two components: meaning of and motivation to travel (Staffieri, 2013). Travel meaning and motivation are significant predictors of the travel to be undertaken and are related to the future outcome of satisfaction (Chang, 2007). There is a difference, though, in the length of the timeframe considered. While the motivation ignites a specific process of decision making leading to a travel choice in the short term (March and Woodside, 2005), the meaning attributed to travel has a more general connotation and goes beyond a specific travel choice or experience (Staffieri, 2013). In other words, values, meaning and motivation for travelling form a chain of influences on present and future travel behaviour.

This study focuses on young travellers because changes and developments in tourism behaviour can be foreseen by describing their present behaviour (Leask et al., 2013). Nevertheless, research on this segment is limited and fragmented (Richards and Wilson, 2003; Staffieri, 2013). Specifically, this paper focuses on university students. They are, in general, of the same age as young travellers (18-30 years old). Compared to young travellers who are not students, they prefer to travel independently from their family (Carr, 2003). Motivation and meaning are best explored when the choice for travelling rests on the traveller and not on his/her parents or another guardian. Therefore the focus on students and independent travel strengthens the coherence of the study.

Summarising, this study explores the social background and values of students' travellers vs the meaning they give to travel and their motivation. The aim is to discover in their present behaviour cues to enhance sustainable travel choices so that the future of tourism can be secured. This study also provides data for predicting tourism choices of youngsters in the more immediate future. It makes a theoretical contribution by testing the suitability and explanatory power of the value scale proposed by De Groot and Steg (2008) in the context of youth tourism and by assessing whether pro-environmental and pro-social values influence the youth tourism experience (Uriely, 2005).

After a literature review, the research method and instruments chosen for this research are introduced. Then the findings are discussed. The conclusion reflects on the main implications of this study for the future of tourism.

\section{Literature review}

This section addresses the areas of study that need to be integrated to assess whether sustainability values influence young travellers needs. It is organised in three subsections: tourism's future and sustainability; values influencing sustainable choices; youth tourism need.

\section{Tourism's future and sustainability}

Tourism's sustainability is a much debated issue. Without any pretension of being exhaustive, Table I illustrates that the impact of tourism on the economic, social and environmental 
Table I Impact on sustainability

\begin{tabular}{lll} 
Dimensions & Impact & Source \\
\hline Economic & 5\% EU GDP & Eurostat (2012) \\
& 3.4 million tourism-related enterprises in EU & Eurostat (2013) \\
& (on 21.5 million non-financial enterprises) & \\
& Often seasonal, low-paid jobs & Postma (2013) \\
Social & 17 million employees in EU & Eurostat (2013) \\
& Mixed impact on local communities & Postma (2013) \\
Environmental & (tourism destination) & \\
& & UNWTO-UNEP-WMO (2008)
\end{tabular}

dimensions of sustainability is often negative, and that thus current tourism development is unsustainable (UNWTO, 2013).

Tourism unsustainability can affect its future both directly and indirectly. Directly, it can damage its natural or cultural basis. Consider, for example the impact that the rise of sees' levels might have on costal destinations such as the Maldives (Becken and Hay, 2012). Indirectly, it can bring its social license to operate (SLO) in danger. SLO refers to the acceptance by society of business activities. A SLO is lost when society concludes that the economic value created by a business is outweighed by its negative impact in other areas (Williams et al., 2007).

That tourism might lose its SLO has been powerfully illustrated with the concept of "assault on pleasure" (Yeoman, 2011). Building on existing studies, Yeoman argues that by 2030 the New Puritans might forego the pleasure of tourism due to the negative impact it has on other values they cherish, such as a healthy natural environment or strong social ties. Though a ban on tourism might seem farfetched, society is definitely aware of the negative environmental pressure of tourism (Yeoman, 2011).

Framed from a sociopsychological perspective the future of tourism implies a dilemma between self-enhancing values (a pleasurable experience) and self-transcending ones (protection of the environment and communities from the disruptive effects of tourism). Sustainable tourism, though, might offer a path to reconcile both sets of values. It is a form of tourism that creates value on an economic, environmental and social dimension (UNWTO, 2013; Timmermans and Cavagnaro, 2013). The three-dimensionality of sustainability is a point that should be insisted on, as a form of tourism that respects the environment and promotes the well-being of local communities but is not economically feasible will not be sustainable in the long run (Yeoman, 2012).

Summarising: the future of tourism might be at stake if self-enhancement values and selftranscendent values are not reconciled in the choice for a more sustainable tourism experience. This explains the interest in exploring how values influence sustainable tourism behaviour.

\section{Values influencing sustainable choices}

The casual model of environmental concern introduced by Stern et al. (1995) clarifies the mutual position and relationship of factors influencing behaviour. The model individuates five antecedents of a specific behaviour. These antecedents form a hierarchy, from the most general and influential to the least general and influential. The social structure in which individuals are embedded shapes early experiences and is therefore set at the beginning of the chain. Values form the next step.

Values are defined as "desirable trans-situational goals varying in importance, which serve as a guiding principle in the life of a person or other social entity" (Schwartz, 1994, p. 21). Values are formed early in life, encompass broad dispositions and orientations, and are therefore considered to be more stable than other factors influencing behaviour. Thanks to their stability values not only influence present choices, but also future ones. This highlights the importance of understanding the influence of the individual's position in the social structure and his/her values when explaining (future) behavioural choices. 
Schwartz (1994) found evidence for a general value system in which values are plotted on two axes, one representing openness to change vs conservatism, and the other representing selfenhancement values (reflecting a concern with a person's own interest) vs self-transcendent values (reflecting a concern with collective interests). This last distinction has been widely used to explain pro-environmental behaviour.

Self-enhancement values that have been shown to have an influence (mostly negative) on pro-environmental choices are social power, wealth, authority, influence and ambition (Table II). This set of values has been labelled as "egoistic" (Stern and Dietz, 1994). Two sets of self-transcendent values influence sustainable choices: altruistic and biospheric. While altruistic values reflect care and concern for other human beings, biospheric values reveal a concern for nature for its own sake, without a direct reference to humans' welfare (De Groot and Steg, 2008). Lately (Steg et al., 2012), hedonic values have been added as a fourth value orientation relevant for explaining sustainable behaviour. As it may be contended that hedonic values are strongly related to a leisurely experience such as travelling, this study investigates whether these four value orientations influence students' need to travel.

To make the link between the value orientations and sustainability more visible, it has recently been proposed to incorporate the four value orientations into three dimensions of care that correspond with the three dimensions of sustainability (Cavagnaro and Curiel, 2012) (Table II).

\section{Youth tourism need}

Youth tourism is a dynamic and booming phenomenon of growing importance (Richards, 2006) and is of particular interest to policy makers and researchers (United Nations World Tourism Organization, and World Youth Student \& Educational Travel Confederation (UNWTO and WYSE), 2011). Studying youth tourism provides a descriptive and interpretative framework of future travellers in the medium to long term because younger generations constitute an innovative element in society and create behavioural tendencies that lead to the emergence of new approaches to tourism (Fermani et al., 2011).

As Richards (2006) observes: "there is still relatively little information available on the development of student and youth tourism worldwide" (p. 97). A sensitive gap is the lack of knowledge on the need of young people to embark on a tourism experience. The general need to travel is brought to the surface by the meaning associated with travelling while motivations start the decision-making process leading to a specific travel experience (Chang, 2007). Meaning and motivation are therefore both oriented to a future behavioural choice.

The sociological literature defines motivation as "a crucial element of human action" distinguishable in intrinsic and extrinsic motivation (Fermani et al., 2011, p. 88). Though it has been suggested that tourists are unaware of the real motivations for their travel because tourism is a social ritual or a venue to resolve unconscious tensions (Dann, 1981; Huang, 2010), the majority of researchers believes that it is possible to unravel tourism motivations. From a tourism perspective, the major distinction is between sociopsychological factors internal to the individual (push) and factors of attraction external to the individual (pull) but related to tourist destination attractiveness (Crompton, 1979; Fermani et al., 2011). Table III summarises research on motivations using this distinction.

Dall'Ara (1990) offers a theoretical framework of considerable interest because it synthetises the aforementioned literature under three dimensions: "the self", "the other self" and "inside itself".

Table II Value orientations and care dimensions

\begin{tabular}{llll} 
Schwartz axes & Values & Care dimension & Sustainability dimension \\
\hline Self-enhancement & $\begin{array}{l}\text { Social power, wealth, authority, influential, ambitious } \\
\text { Pleasure, enjoying life, self-gratification }\end{array}$ & Care for me & Economic \\
Self-transcendent & $\begin{array}{l}\text { Equality, a world at peace, social justice, helpful } \\
\text { Respecting the earth, unity with nature, } \\
\text { protecting the environment, preventing pollution }\end{array}$ & Care for me and you & Social \\
& & Care for all & Environmental
\end{tabular}

VOL. 1 NO. $22015 \mid$ JOURNAL OF TOURISM FUTURES | PAGE 97 
Table III Motivations

\begin{tabular}{|c|c|c|}
\hline Motivation & Description & Main references \\
\hline Unconscious & & Dann (1981), Huang (2010), \\
\hline Conscious - push & Destination attractiveness & $\begin{array}{l}\text { Crompton (1979), } \\
\text { Fermani et al. (2011) }\end{array}$ \\
\hline \multirow[t]{9}{*}{ Conscious - pull } & Family socio-economic background & Ferrari (2004), \\
\hline & Tourism biography & Fermani et al. (2011) \\
\hline & Interrupt the daily routine & \\
\hline & Undertake unusual activities & \\
\hline & Seek novelty in places other than the reference context & \\
\hline & Increase the wellbeing & \\
\hline & Live in contact with nature & \\
\hline & Socialise with friends and family & \\
\hline & Follow the fashion trends & \\
\hline
\end{tabular}

In the first dimension, the main reason leading people to travel is the need to restore a balance, both physical and mental. In the dimension "the other self" tourism equals transgression. The last dimension prompts travelling to get into deep contact with one's own identity.

It should be noted that the desire of experiencing is a core driving force of student travel. Young students desire to be involved on their travels, and are willing to skimp on services costs to invest more in lifetime experiences (Richards and Wilson, 2003). The longing for experiences is also central to the UNWTO definition of youth travel: all independent trips for periods of less than one year by people aged 16-29 which are motivated, in part or in full, by a desire to experience other cultures, build life experience and/or benefit from formal and informal learning opportunities outside one's usual environment (United Nations World Tourism Organization, and World Youth Student \& Educational Travel Confederation (UNWTO and WYSE), 2008).

Concluding, the main issues for investigation emerging from the literature are whether position in the social structure and sustainable value orientations influence the general need to travel of young tourists and which are the main meaning and motivation assigned by them to travelling.

\section{Research method}

The issues emerged from the literature require an empiric methodological approach geared towards the analysis of relationships among variables. To this aim a Computer Assisted Web Interview (CAWI) was conducted at Stenden University of Applied Sciences in the Netherlands in 2013[1]. CAWI records information in a standardised way and provides therefore good quality data. CAWI's specific limitation (internet access) is less problematic for the researched population, the so-called digital generation. The sample technique used is a non-probability sampling. Comfrey and Lee (1992) consider 300 cases a good sample size. After two reminders 365 students participated in the survey. This resulted in 274 properly filled out questionnaires. For an explorative study a sample size of 274 is appropriate. Moreover, the sample has been validated with respect to the age of Stenden students.

Table IV illustrates the scales used to measure structural variables and values. These scales have proven robust in previous research.

Cronbach's $\alpha$ coefficients were used to verify the consistency of the scales and principal component analyses (PCA)[2] to verify the unidimensionality of the values (Table V).

The internal consistency of the biospheric and altruistic value orientation scales is strong, while that of the other two scales is weaker. Though this has no immediate consequences for the explorative analysis in this study, it suggests the need to reinforce the weaker scales by adding other items and testing them anew in the context of youth tourism.

Using the median value as a discriminator, the four value orientations were considered as independent variables in logistic models[3]. Table VI summarises the dependent variables 
Table IV Structural variables and values' scales

\begin{tabular}{|c|c|c|c|}
\hline Variable & Dimension & Category & Note \\
\hline \multirow{4}{*}{$\begin{array}{l}\text { Position in social } \\
\text { structure }\end{array}$} & Gender & & \\
\hline & Age class & $17-20,21-25,26-32$ & \\
\hline & Level of education of the parents & $\begin{array}{l}\text { Low, i.e. no title or elementary } \\
\text { school; medium, i.e. high } \\
\text { school; high, i.e. tertiary } \\
\text { education }\end{array}$ & $\begin{array}{l}\text { Proxy for income level (Glick and } \\
\text { Miller, 1956; De Gregorio and Lee, } \\
\text { 2002) }\end{array}$ \\
\hline & Family travel experience in the last ten years & Yes/no & \\
\hline \multirow[t]{4}{*}{ Value orientation } & Hedonic & Nine-point Likert scale & Steg et al. (2012) \\
\hline & Egoistic & & \\
\hline & Altruistic & & \\
\hline & Biospheric & & \\
\hline
\end{tabular}

Table V Cronbach's $\alpha$ and PCA

\begin{tabular}{|c|c|c|c|c|}
\hline Values & Items & Cronbach's $\alpha$ & $K M O^{a}$ & Variance (\%) \\
\hline Egoistic & Social power, wealth, authority, influential and ambitious & 0.697 & 0.703 & 46.0 \\
\hline Hedonic & Pleasure, enjoying life, gratification for oneself & 0.610 & 0.642 & 56.0 \\
\hline Altruistic & Equality, a world at peace, social justice, helpful & 0.719 & 0.739 & 55.0 \\
\hline Biospheric & Respecting the earth, unity with nature, protecting the environment, preventing pollution & 0.862 & 0.766 & 71.0 \\
\hline
\end{tabular}

of these models. The choice of the dependent variables reflects the focus of the study on travel needs.

Considering the existing diversity of approaches towards the concept of meaning and motivation, the survey developed includes statements based on the literature summarised in Table III. Respondents were asked to indicate their level of agreement with these statements using a fivepoint Likert scale. A PCA was used to reduce the measured items and to discover the main relations between them. The new components, transformed into a binary variable by considering the median score, were then used as dependent variables in a series of logistic models.

The PCA shows that the 14 items on travel meaning consist of five components: Growth and development, Sustainability, Socialising, Entertainment, and Escapism and relaxation (Table VI). The first component encompasses both the dimensions of "the self" and the dimension of "inside self" individuated by Dall'Ara (1990). The second component is related to the need to live authentically, to live in contact with local people and with nature. This component reflects the "intrinsic meaning prospective" derived from psychological literature and is in line with the definition of sustainability at the individual level as care for the self, others and nature (Cavagnaro and Curiel, 2012). The label "Sustainability" is therefore appropriate. The third component is formed by the need to meet many people and to find new friends. It represents well the dimension of "other self" (Dall'Ara, 1990). Very close to the third component, but more related to the concept of transgression, is the fourth component. The last component represents a wellattested need in the literature: escapism and relaxation.

The 11 items describing travel motivation consist of three components: Culture, Escapism and relaxation, and Vogue (Table VI). "Culture" sublimates the "push" (to know different cultures, feel independent, interact with other people, study/work) and "pull" (seeing the beauty of the place) dichotomy supported by Crompton (1979). "Escapism and relaxation" is in line with the last travel meaning individuated above. "Vogue" recognises the influence of fashion trends on travel needs, an aspect underlined by psychological literature (Blumer, 1969). 
Table VI Tourism experience - need component (meaning and motivation)

\begin{tabular}{|c|c|c|c|}
\hline Need & Dependent variables & Item & Description \\
\hline \multirow[t]{5}{*}{ Meaning } & Growth and development & $\begin{array}{l}\text { Discover and experience new cultures } \\
\text { Explore different ways of life grow } \\
\text { Acquire and deepen knowledge of art or } \\
\text { history change }\end{array}$ & $\begin{array}{l}\text { Binary variable, built considering the median } \\
\text { value of the first component (FC) obtained from } \\
\text { PCA, of the } 14 \text { items related to the concept of } \\
\text { meaning } \\
\text { FC variance explained }=23.5 \% \\
\text { Total variance explained }=71.6 \% \\
\mathrm{KMO}=0.803\end{array}$ \\
\hline & Sustainability & $\begin{array}{l}\text { Live in contact with nature } \\
\text { Live authentically } \\
\text { Live in contact with local people }\end{array}$ & $\begin{array}{l}\text { Binary variable, built considering the median } \\
\text { value of the second component }(\mathrm{SC}) \\
\text { SC variance explained }=14.6 \%\end{array}$ \\
\hline & Socialising & $\begin{array}{l}\text { Meet many people } \\
\text { Find new friends }\end{array}$ & $\begin{array}{l}\text { Binary variable, built considering the median } \\
\text { value of the third component (TC) } \\
\text { TC variance explained }=13.5 \%\end{array}$ \\
\hline & Entertainment & $\begin{array}{l}\text { Be with friends } \\
\text { Enjoy entertainment (nightlife, pubs) }\end{array}$ & $\begin{array}{l}\text { Binary variable, built considering the median } \\
\text { value of the fourth component (FoC) } \\
\text { FoC variance explained }=10.5 \%\end{array}$ \\
\hline & Escapism and relaxation & $\begin{array}{l}\text { Escape from everyday life } \\
\text { Rest and relax }\end{array}$ & $\begin{array}{l}\text { Binary variable, built considering the median } \\
\text { value of the fifth component }(\mathrm{FiC}) \\
\mathrm{FiC} \text { variance explained }=9.5 \%\end{array}$ \\
\hline \multirow[t]{3}{*}{ Motivation } & Culture & $\begin{array}{l}\text { Learn about different cultures } \\
\text { Feel more independent } \\
\text { Interact with other people } \\
\text { Study/or work } \\
\text { See the beauty of the place }\end{array}$ & $\begin{array}{l}\text { Binary variable, built considering the median } \\
\text { value of the first component (FC) obtained from } \\
\text { PCA, of the } 11 \text { items related to the concept of } \\
\text { motivation } \\
\text { FC variance explained }=22.7 \% \\
\text { Total variance explained }=60.2 \% \\
\mathrm{KMO}=0.700\end{array}$ \\
\hline & Escapism and relaxation & $\begin{array}{l}\text { Have fun } \\
\text { Relax } \\
\text { Have a break from everyday life } \\
\text { Interact with my friends }\end{array}$ & $\begin{array}{l}\text { Binary variable, built considering the median } \\
\text { value of the second component (SC) } \\
\text { SC variance explained }=22.2 \%\end{array}$ \\
\hline & Vogue & $\begin{array}{l}\text { Most people think that you should do that at } \\
\text { least once in life } \\
\text { I discussed my plans beforehand with friends } \\
\text { on Facebook }\end{array}$ & $\begin{array}{l}\text { Binary variable, built considering the median } \\
\text { value of the third component (TC) } \\
\text { TC variance explained }=15.3 \%\end{array}$ \\
\hline
\end{tabular}

As stated previously, relationships were tested using logistic models. Following Stern et al. (1995), the sociodemographic characteristics were considered as predictors of the value orientation and together they were considered as predictors of the tourism experience. The goodness of fit of the logistic models was tested using the Hosmer-Lemeshow (HL) test, which is particularly suitable for small sample sizes. If the $\mathrm{HL}$ test statistic is not significant, the model fit is acceptable (Hosmer and Lemeshow, 2000). The HL statistic test confirms the goodness of fit for all of the logistic regression models carried out.

\section{Results and discussion}

This study focuses on independent travel to ascertain the meaning and motivation of young tourists to travel. Therefore, only questionnaires completed by students who had travelled independently at least once in the last two years were considered valid. A total of 274 valid questionnaires were received.

Respondents' age ranged between 17 and 32 years. Students aged between 21 and 25 years represented the predominant age group (63.2 per cent), followed by 17 and 20 years old (27.7 per cent) and the 26 and 32 year old groups (9.1 per cent). The majority of respondents were Dutch (55.5 per cent), followed by Germans (27.0 per cent) and Chinese (7.7 per cent). This mix is consistent with the international character of the university where the survey was taken (Stenden). The limited number of cases did not support further analysis on nationality. Compared 
to Stenden student population, women are overrepresented in our sample (82.1 per cent). This reflects a tendency found in all surveys set out at Stenden.

This section presents and briefly discusses results on:

- the influence of sociodemographic characteristics on the value orientation; and

- the influence of sociodemographic characteristics and of the value orientations on travel need.

\section{Sociodemographic characteristics and value orientation}

This study considers four proxy variables for sociodemographic characteristic: gender; class age; family educational level and family tourism curriculum. Of these four only the last does not present significant correlation with value orientations. The literature, though, insists on the importance of the family tourist curriculum for the forming of young travellers (MacCannell, 1976). One explanation of this finding is that the family tourism curriculum is measured as presence/ absence with only one statement. Future research might strengthen this variable with questions on the number of travel experiences, their length and destination.

Several studies on the relationship between gender and sustainability conclude that men tend to hold weaker pro-environmental attitudes than women (Diamantopoulos et al., 2003). This conclusion is indirectly supported: men score higher than women on the egoistic value orientation. This value orientation is considered antagonist to sustainable behaviour (Lindenberg and Steg, 2007).

The age class is a significant predictor of the egoistic and hedonic value orientation. The higher the age class, the higher the egoistic value orientation becomes while the hedonic value orientation decreases. A possible explanation lies in the literature on subjective emotional well-being, where it is suggested that pleasant effects tend to decline with age (Diener and Lucas, 2000). For tourism's future this is an interesting result: if this tendency continues a tourism offer centred on enjoyment and pleasure will be less appealing to travellers from ageing societies.

The family educational level positively affects the hedonic value orientation. It is expected that the family background influences youth values and behaviour (Bourdieu, 1979), yet the specific influence found here is new. Further research is needed to assess whether families with a more secure economic situation encourage their studying children to seek pleasure and enjoyment when travelling rather than focusing on more normative goals (Table VII).

\section{Sociodemographic characteristics, value orientation and students' travel need}

This section presents and briefly discusses the significant relationships between the sociodemographic characteristic and the four value orientations on the one hand and the need dimension of the travel experience on the other. The influence of sociodemographic

Table VII Results of the logistic regression model on sociodemographic characteristics and value orientation

\begin{tabular}{|c|c|c|c|c|c|c|c|c|c|c|c|c|}
\hline & \multicolumn{3}{|c|}{ Egoistic } & \multicolumn{3}{|c|}{ Hedonic } & \multicolumn{3}{|c|}{ Altruistic } & \multicolumn{3}{|c|}{ Biospheric } \\
\hline & Coeff B & Sig. & $\operatorname{Exp}(B)$ & Coeff B & Sig. & $\operatorname{Exp}(B)$ & Coeff B & Sig. & $\operatorname{Exp}(B)$ & Coeff B & Sig. & $\operatorname{Exp}(B)$ \\
\hline \multicolumn{13}{|c|}{ Gender (ref female) } \\
\hline Male & 0.698 & $0.043^{\star *}$ & 2.009 & 0.131 & 0.714 & 1.140 & -0.404 & 0.221 & 0.668 & -0.308 & 0.352 & 0.735 \\
\hline \multicolumn{13}{|c|}{ Class age (ref 17-20) } \\
\hline $21-25$ & 0.158 & 0.579 & 1.171 & -0.557 & $0.070^{*}$ & 0.573 & 0.041 & 0.885 & 1.042 & 0.229 & 0.417 & 1.257 \\
\hline $26-32$ & 1.069 & $0.040^{\star *}$ & 2.912 & 0.726 & 0.198 & 2.066 & 0.297 & 0.538 & 1.346 & 0.777 & 0.116 & 2.175 \\
\hline \multicolumn{13}{|c|}{ Educational family level (ref low) } \\
\hline Medium & -0.360 & 0.385 & 0.698 & 0.817 & $0.061^{*}$ & 2.265 & 0.435 & 0.283 & 1.545 & 0.501 & 0.219 & 1.650 \\
\hline High & -0.449 & 0.241 & 0.638 & 0.643 & 0.109 & 1.903 & 0.325 & 0.384 & 1.385 & 0.467 & 0.215 & 1.595 \\
\hline \multicolumn{13}{|c|}{ Tourism family curriculum (ref no) } \\
\hline Yes & -0.529 & 0.235 & 0.589 & 0.501 & 0.259 & 1.651 & -0.175 & 0.674 & 0.839 & -0.091 & 0.829 & 0.913 \\
\hline Constant & 0.540 & 0.347 & 1.716 & -0.625 & 0.280 & 0.535 & -0.120 & 0.824 & 0.887 & -0.476 & 0.383 & 0.621 \\
\hline
\end{tabular}


characteristics is discussed first, followed by the influence of values. As stated above, the dimension "need" consists of two components, meaning and motivation. Meaning will be discussed first and then motivation.

As the PCA has shown, meaning has five different connotations. Sociodemographic characteristics influence the attribution of all the connotations of meaning (Table VIII). Results suggest that women are more likely than men to choose the meaning "Growth and development". This result confirms the outcomes of a recent study on the travel experience of Italian young tourists (Staffieri, 2013) and might be interpreted with reference to the increased freedom of movement experienced by women after the 1950s (Yeoman and Butterfield, 2011) and to their increased propensity to travel and reach foreign destinations (Leed, 1991). Against this background, literature has shown that women's motivation to travel is often to know new cultures and to study and that, consequently, the destinations chosen by women are dense with meaning and allow the traveller to grow, develop and realise her own self (Ruspini et al., 2013).

Unsurprisingly, women more than men choose the meaning "Sustainability". This outcome supports the above-mentioned need for women to experience personal growth and profound contact with people and places. Furthermore it concurs with literature suggesting that women have a higher pro-environmental attitude than men (Diamantopoulos et al., 2003).

Older respondents choose more often than younger respondents the meaning "Sustainability" and "Escapism and relaxation" and less often "Socialising" and "Entertainment". This is in line with the decrease of hedonic values with age. Students who come from families with a higher educational level choose more often the meaning "Growth and development" and less often the meaning "Escapism and relaxation". This might be interpreted with reference to literature on the influence of the sociocultural background on consumption (Bourdieu, 1979): while people from a wealthy family attribute a symbolic meaning to consumption (identity and social status), people from a less privileged background, having experienced some degree of hardship, are more sensitive to the immediate functionality and practicality of an object (Martinengo and Savoja, 1993).

The tourism family curriculum has no influence on the meaning associated with travel. Linked to the absence of an influence on the value orientations as well, this result casts a negative light on the usefulness of this variable as a proxy for the social position of an individual.

Out of the four value orientations, the egoistic one does not influence any component of meaning. In other words, this category of self-enhancement value has no grip on meanings associated with travel. The reason might be twofold. First, as stated before, youth travel is strongly linked to personal growth and development and thus to values that suppose at least a minimum degree of transcendence (United Nations World Tourism Organization (UNWTOUNEP-WMO), 2008). Second, it may be contested that in the list of motivations derived from the existing literature, no allowance is made for travelling as a means to enhance personal power or influence, i.e. egoistic values. Future research is needed to decide which of these two explanations is the most plausible.

As expected, the second set of self-enhancement values, hedonic values, is positively and strongly related to the meaning "Entertainment". It also influences the association of travel with the meaning "Socialising" and "Escapism and relaxation". Hedonic values are connected with having pleasure in the present moment (Steg et al., 2012). Literature on young travellers also suggests that having fun with friends and socialising are important needs (UNWTO and WYSE, 2011).

Students with an altruistic value orientation are more likely than others to associate travel with the meaning "Growth and development". These needs are not catered by the mostly brief and superficial encounters of nightlife, which might explain why these respondents have lower propensity than others to associate travel with the meaning "Entertainment".

Unsurprisingly respondents with a biospheric value orientation are more likely to associate travel with the meaning "Sustainability". Biospheric values strongly influence pro-environmental behaviour and are intimately linked to altruistic values (De Groot and Steg, 2008). Both biospheric and altruistic values are self-transcendent values: they presuppose the ability to surpass the self and meaningfully connect with other people and nature (Schwartz, 1994). Authenticity, interpreted as development of the personal identity and genuineness of emotions

PAGE 102 | JOURNAL OF TOURISM FUTURES | VOL. 1 NO. 22015 


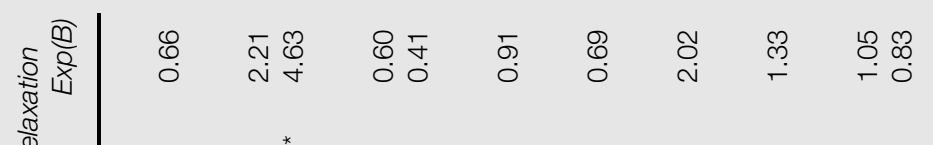

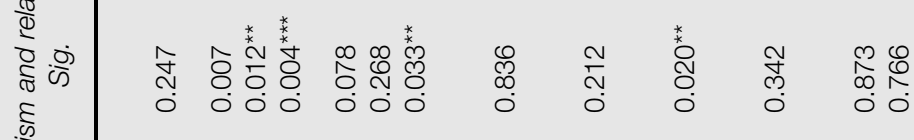

番爱

商

商要

童

商

总它

可

可

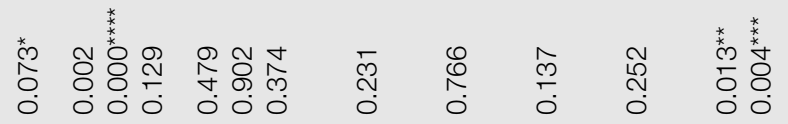
包

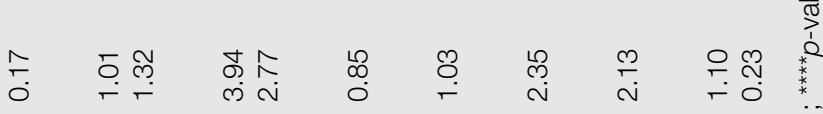

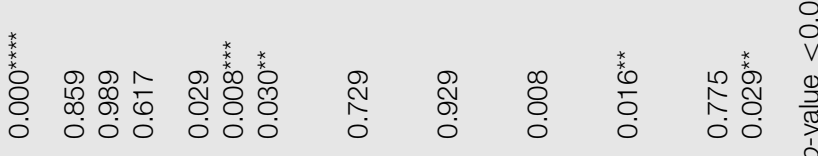

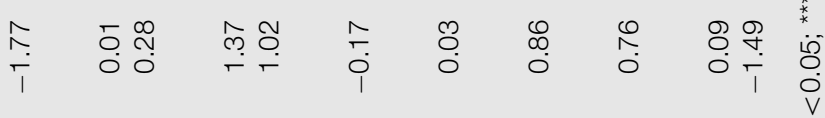

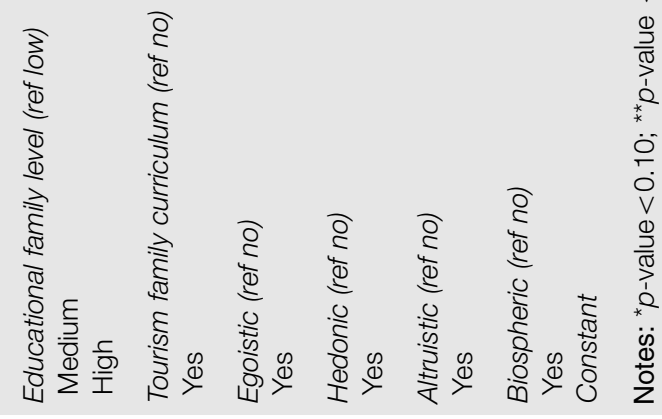


(UNWTO and WYSE, 2008), forms the basis from which transcendence is possible (Cavagnaro and Curiel, 2012).

The second component of travel needs is motivation (Table IX). Motivation is in some respects influenced by sociodemographic factors, such as gender: women are more likely than men to travel for cultural needs (Ruspini et al., 2013) and less likely to travel for vogue or in search of rest and relaxation. The family background influences the motivation related to rest and relaxation: the likeliness for this reason decreases the higher the family educational level.

A counterintuitive result is that the motivation "Vogue" is positively influenced by the touristic family curriculum and negatively by an altruistic value orientation. This result can be interpreted by pointing to the difference between altruism (intrinsic motivation to relate with others) and conformity and tradition (extrinsic motivation). Conformity and tradition share the goal to subordinate the self in favour of social expectations (Schwartz, 1994).

Interestingly, respondents with a biospheric value orientation are more likely to motivate their travel in terms of taking a break and relaxing and to associate to it the meaning connecting with nature. This can possibly be explained by the "biophilia" theory. This suggests that people receive physical benefits by being in contact with nature (Kellert and Wilson, 1993). This explanation is also supported by findings from Fermani et al. (2011) who also reported a strong influence of an other-orientated personality on the choice of travelling for novelty, rest and being in contact with nature.

\section{Conclusions}

Considering the projected growth of tourism on the one hand and the negative impact of tourism on the natural environment and hosting community on the other, this study aims to assure tourism a future by exploring whether sustainability values influence the general (i.e. not directly related to sustainability) travel needs of students. Results suggest that this is the case.

Moreover, the technique used in analysing the data, where two groups were distinguished for each variable, allows us to state that half of the respondents are already influenced in their

Table IX Results of the logistic regression model on value orientations and family background and travel motivations

\begin{tabular}{|c|c|c|c|c|c|c|c|c|c|}
\hline & & Culture & & & $m$ and rela & & & Vogue & \\
\hline & Coeff B & Sig. & $\operatorname{Exp}(B)$ & Coeff B & Sig. & $\operatorname{Exp}(B)$ & Coeff B & Sig. & $\operatorname{Exp}(B)$ \\
\hline Gender (re & nale) & & & & & & & & \\
\hline Male & -1.320 & $0.001^{\star \star \star}$ & 0.267 & 0.709 & $0.056^{\star}$ & 2.032 & 0.854 & $0.022^{* *}$ & 2.350 \\
\hline Class age & 17-20) & & & & & & & & \\
\hline $21-25$ & -0.072 & 0.819 & 0.931 & -0.137 & 0.660 & 0.872 & -0.245 & 0.426 & 0.782 \\
\hline 26-32 & -0.673 & 0.207 & 0.510 & -0.261 & 0.614 & 0.770 & -0.388 & 0.455 & 0.678 \\
\hline Educationa & nily level (r & & & & & & & & \\
\hline Medium & 0.655 & 0.152 & 1.926 & -0.811 & $0.075^{\star}$ & 0.444 & -0.381 & 0.388 & 0.683 \\
\hline High & 0.694 & 0.101 & 2.001 & -0.993 & $0.019^{\star \star}$ & 0.370 & -0.214 & 0.599 & 0.808 \\
\hline Tourism fa & curriculum & no) & & & & & & & \\
\hline Yes & 0.263 & 0.568 & 1.301 & -0.076 & 0.865 & 0.927 & 0.880 & $0.057^{*}$ & 2.411 \\
\hline Egoistic (re & & & & & & & & & \\
\hline Yes & 0.389 & 0.179 & 1.476 & -0.290 & 0.309 & 0.748 & 0.220 & 0.438 & 1.246 \\
\hline Hedonic (r & & & & & & & & & \\
\hline Yes & 0.052 & 0.850 & 1.053 & -0.291 & 0.283 & 0.748 & 0.159 & 0.558 & 1.172 \\
\hline Altruistic (r & & & & & & & & & \\
\hline Yes & 0.124 & 0.670 & 1.132 & -0.259 & 0.374 & 0.772 & -0.587 & $0.042^{\star \star}$ & 0.556 \\
\hline Biospheric & no) & & & & & & & & \\
\hline Yes & 0.173 & 0.570 & 1.188 & 0.803 & $0.009^{\star \star \star}$ & 2.233 & 0.230 & 0.444 & 1.259 \\
\hline Constant & -0.863 & 0.177 & 0.422 & 0.867 & 0.166 & 2.379 & -0.590 & 0.341 & 0.554 \\
\hline
\end{tabular}

PAGE 104 | JOURNAL OF TOURISM FUTURES | VOL. 1 NO. 22015 
present choices by biospheric values, and so in the future could be nudged to adopt a more sustainable travel attitude and behaviour. In other words: there is potential to develop sustainable tourism beyond the niche market on which the industry is focusing. In this context, marketing and education could be used both by industry and governments to nudge young people towards a more sustainable tourism choice by showing them that they already harbour sustainability values and by strengthening these. The success of such an intervention could be the subject of future studies monitoring the change.

Looking to the immediate future, the most interesting target group for a sustainable tourism offer are women because they harbour stronger sustainability values than men. Women moreover see travel as an opportunity to grow and develop through engagement with local people and the place visited. The travel industry could therefore design a dedicated offer for young women addressing both their sustainability and development needs.

Another opportunity for the industry is offered by the link of biospheric value orientation with sustainability as a meaning associated with travel and escapism and relaxation as a motivation to travel. Here, too, special packages could be designed and promoted to youngsters.

Also interesting from a future perspective is the declining importance of hedonism with age, a result that might suggest that in ageing societies travel will be increasingly less valued for the opportunity it offers for pleasurable enjoyment. The recent economic downturn might counteract this tendency, however, as the results show that young people from a less privileged social background seek pleasure in their travel experience.

This study on values and young tourists' needs undoubtedly sheds some light on tourism's future developments. Yet further research is needed to strengthen the scales and models introduced or used here. First, this study should be replicated with a larger sample including both students and non-students to better test the strength of the relationships found. Moreover, the hedonic scale, which shows the lowest Cronbach of all value orientations, should be strengthened. To test the relative impact of sustainability values on meaning and motivation of travel, a follow-up study should include all the values individuated by Schwartz (1994). Travel needs connected to egoistic values might also be better explored. Finally, this study focuses only on the need phase of the travel experience, as that phase is the most future oriented. Subsequent studies should include the other phases of the tourism experience and explore whether the overall travel experience impacts on youth values (UNWTO and WYSE, 2008).

\section{Notes}

1. The questionnaire is send on request to the authors.

2. PCA is a statistical procedure aimed at reducing the number of original variables in a sub set of new variables, called principal components, via an orthogonal transformation. The principal components are uncorrelated (Di Franco and Marradi, 2013). This procedure is based on the correlation matrix of the variables chosen in the analysis.

3. Logistic regression is the most important model for categorical data. It is used in a wide variety of applications also in social science research. The model allows to predict the behaviour of a dependent variable expressed as the presence/absence based on the values of a set of predictor variables (Agresti, 2013).

\section{References}

Agresti, A. (2013), Categorical Data Analysis, 3rd ed., John Wiley \& Sons, Hoboken, NJ.

Becken, S. and Hay, J. (2012), Climate Change and Tourism: from Policy to Practice, Routledge, Oxford.

Blumer, H. (1969), Symbolic Interactionism: Perspective and Method, Prentice Hall, Englewood Cliffs, NJ.

Bourdieu, P. (1979), La distinction, Les Éditions de Minuit, Paris.

Carr, N. (2003), "University and college students' tourism”, in Ritchie, B.W. (Ed.), Managing Educational Tourism, Channel View Publications, Clevedon, pp. 181-225.

Cavagnaro, E. and Curiel, G. (2012), The Three Levels of Sustainability, Greenleaf Publishing, Sheffield. 
Chang, J.C. (2007), "Travel motivations of package tour travelers", Original Scientific Paper, Vol. 55 No. 2, pp. 157-76.

Comfrey, A.L. and Lee, H.B. (1992), A First Course in Factor Analysis, Lawrence Erlbaum Associates, Hillsdale, NJ.

Crompton, J.L. (1979), "Motivation for pleasure vacation”, Annals of Tourism Research, Vol. 6 No. 1, pp. 409-24.

Dall'Ara, G. (1990), Perché le persone vanno in vacanza?, FrancoAngeli, Milano.

Dann, G.M.S. (1981), “Tourism motivation: an appraisal”, Annals of Tourism Research, Vol. 8 No. 2, pp. 187-219.

De Gregorio, J. and Lee, J. (2002), "Education and income inequality: new evidence from cross-country data", The Review of Income and Wealth, Vol. 48 No. 3, pp. 395-416.

De Groot, J.I.M. and Steg, L. (2008), "Value orientations to explain beliefs related to environmentally significant behavior: how to measure egoistic, altruistic and biospheric value orientations", Environment and Behavior, Vol. 40 No. 3, pp. 330-54.

Diamantopoulos, A., Schlegelmilch, B.B., Sinkovics, R.R. and Bohlen, G.M. (2003), "Can sociodemographics still play a role in profiling green consumers? A review of the evidence and an empirical investigation", Journal of Business Research, Vol. 56 No. 6, pp. 465-80.

Diener, E. and Lucas, R.E. (2000), "Subjective emotional well-being", in Lewis, M. and Haviland, J.M. (Eds), Handbook of Emotions, Guilford, New York, NY, pp. 325-37.

Di Franco, G. and Marradi, A. (2013), Factor Analysis and Principal Component Analysis, FrancoAngeli, Milano.

Eurostat (2012), "Tourism trends", available at: http://epp.eurostat.ec.europa.eu/statistics_explained/ index.php/Tourism_trends (accessed 31 October 2013).

Eurostat (2013), "Tourism Satellite Accounts (TSAs) in Europe - 2013 edition”, available at: http://epp. eurostat.ec.europa.eu/portal/page/portal/product_details/publication?p_product_code=KS-TC-13-006 (accessed 10 October 2014).

Fermani, A., Crocetti, E. and Carradori, D. (2011), I Giovani e la Vacanza: Tratti di Personalità e Motivazione alla Scelta, Edizioni Università di Macerata, Macerata.

Ferrari, M. (2004), Come si Diventa Turisti. Teoria e Indagine Empirica sui Comportamenti Turistici, Cuec, Cagliari.

Glick, P.C. and Miller, H.P. (1956), "Educational level and potential income", American Sociological Review, Vol. 21 No. 3, pp. 307-12.

Hosmer, D.W. and Lemeshow, S. (2000), Applied Logistic Regression, 2nd ed., John Wiley and Sons, New York, NY.

Huang, S. (2010), "Measuring tourist motivation: do scales matter?", Tourismos, An international Multidisciplinary Journal of Tourism, Vol. 5 No. 1, pp. 153-62.

Kellert, S.R. and Wilson, E.O. (Eds) (1993), The Biophilia Hypothesis, Island Press, Covelo, CA.

Leask, A., Fyall, A. and Barron, P. (2013), "Generation Y: opportunity or challenge - strategies to engage Generation $Y$ in the UK attractions' sector", Current Issues in Tourism, Vol. 16 No. 1, pp. 17-46.

Leed, E.J. (1991), The Mind of the Traveler. From Gilgamesh to Global Tourism, Basic Book, New York, NY.

Lindenberg, S. and Steg, L. (2007), "Normative, gain and hedonic goal frames guiding environmental behavior", Journal of Social Issues, Vol. 65 No. 1, pp. 117-37.

MacCannell, D. (1976), The Tourist: A New Theory of the Leisure Class, Schocken, New York, NY.

March, R.G. and Woodside, A.G. (2005), Tourism Behavior: Travelers' Decisions and Actions, CABI Publishing, Cambridge.

Martinengo, M.C. and Savoja, L. (1993), Giovani e Turismo. Un'indagine sulle Vacanze Giovanili, FrancoAngeli, Milano.

Perkins, E.E. and Brown, P.R. (2012), "Environmental values and the so-called true ecotourist", Journal of Travel Research, Vol. 51 No. 6, pp. 793-803.

Postma, A. (2013), "When the tourist flew in, critical encounters in the development of tourism", PhD thesis, Faculty of Spatial Sciences, University of Groningen, Groningen.

Richards, G. (2006), "ISTC/UNWTO survey on student and youth tourism among national tourism administrations/organizations", in UNWTO, Tourism Market Trends, 2005 Edition, World Overview \& Tourism Topics, World Tourism Organization, Madrid, pp. 95-123.

PAGE 106 | JOURNAL OF TOURISM FUTURES | VOL. 1 NO. 22015 
Richards, G. and Wilson, J. (2003), New Horizons in Independent Youth and Student Travel. Today's Youth Tourists: Tomorrow's Global Nomads? A Report for the International Student Travel Confederation (ISTC) and the Association of Tourism and Leisure Education (ATLAS), International Student Travel Confederation, Amsterdam.

Ruspini, E., Gilli, M., Decataldo, A. and Del Greco, M. (2013), "Le esperienze turistiche, il genere e le generazioni”, in Ruspini, E., Gilli, M. and Decataldo, A. (Eds), Turismo Generi Generazioni, Zanichelli, Bologna, pp. IX-XVI.

Schwartz, S.H. (1994), "Are there universal aspects in the structure and contents of human values?", Journal of Social Issues, Vol. 50 No. 4, pp. 19-45.

Staffieri, S. (2013), "L'esperienza turistica dei giovani italiani” (“The tourism experience of young Italian”), PhD thesis, La Sapienza, Università di Roma, Roma.

Steg, L. and Vlek, C. (2009), "Encouraging pro-environmental behaviour: an integrative review and research agenda", Journal of Environmental Phycology, Vol. 29 No. 3, pp. 309-17.

Steg, L., Perlaviciute, G., van der Werff, E. and Lurvink, J. (2012), "The significance of hedonic values for environmentally relevant attitudes, preferences, and actions”, Environment and Behavior, Vol. 46 No. 2, pp. 163-92.

Stern, P.C. and Dietz, T. (1994), "The value basis of environmental concern", Journal of Social Issues, Vol. 50 No. 3, pp. 65-84.

Stern, P.C., Dietz, T. and Guagnano, G.A. (1995), "The new ecological paradigm in social-psychological context", Environment and Behavior, Vol. 27 No. 6, pp. 723-43.

Tepelus, M.C. (2005), "Aiming for sustainability in the tour operating business", Journal of Cleaner Production, Vol. 13 No. 2, pp. 99-107.

Thøgersen, J. and Ölander, F. (2003), "Spillover of environment-friendly consumer behaviour", Journal of Environmental Psychology, Vol. 23 No. 3, pp. 225-36.

Timmermans, R. and Cavagnaro, E. (2013), "Beyond the hype. In 2035 sustainability is mainstream. What does it take for tourism to meet this challenge?", in Postma, A., Yeoman, I. and Oskam, J. (Eds), The Future of European Tourism, European Tourism Futures Institute, Leeuwarden, pp. 150-76.

United Nations World Tourism Organization (UNWTO) (2013), Tourism Highlights, 2013 ed., UNWTO, Madrid. United Nations World Tourism Organization (UNWTO-UNEP-WMO) (2008), Climate Change and Tourism: Responding to Global Challenges, UNWTO, Madrid.

United Nations World Tourism Organization, and World Youth Student \& Educational Travel Confederation (UNWTO and WYSE) (2008), Youth Travel Matters: Understanding the Global Phenomenon of Youth Travel, World Tourism Organization, Madrid.

United Nations World Tourism Organization, and World Youth Student \& Educational Travel Confederation (UNWTO and WYSE) (2011), The Power of Youth Travel, World Tourism Organization, Madrid.

Uriely, N. (2005), "The tourist experience, conceptual developments", Annals of Tourism Research, Vol. 32 No. 1, pp. 199-216.

Williams, P., Gill, A. and Ponsford, I. (2007), "Corporate social responsibility at tourism destinations: toward a social license to operate", Tourism Review International, Vol. 11 No. 2, pp. 133-44.

Yeoman, I. (2011), Tomorrow's Tourist, Scenarios and Trends, Routledge, Abingdon.

Yeoman, I. (2012), 2050 - Tomorrow's Tourism, Channel View Publications, Bristol.

Yeoman, I. and Butterfield, S. (2011), "Tourism and demography: an overview”, in Yeoman, I., Hsu, C.H.C., Smith, K. and Watson, S. (Eds), Tourism and Demography, Goodfellow, Oxford, pp. 1-21.

\section{Further reading}

United Nations World Tourism Organization (UNWTO) (1994), Recommendations on Tourism Statistics, UN Statistical Papers, New York, NY.

\section{Corresponding author}

Dr Elena Cavagnaro can be contacted at: elena.cavagnaro@stenden.com 